\title{
Long term safety of infliximab
}

\author{
Thomas F Schaible PhD
}

\begin{abstract}
TF Schaible. Long term safety of infliximab. Can J Gastroenterol 2000;14(Suppl C):29C-32C. Infliximab is a chimeric anti-tumour necrosis factor-alpha monoclonal antibody that has been studied for the treatment of Crohn's disease and rheumatoid arthritis. In several placebo controlled, randomized clinical trials and open trials, 771 patients have been given infliximab (a further 192 received placebo). Follow-up for safety has included the time of study (12 weeks after the last infusion), plus three additional years. Acute infusion reactions (headache, fever, chills, urticaria, chest pain) were seen in $17 \%$ of patients receiving infliximab compared with $7 \%$ of those receiving placebo. While infections were reported more frequently overall in the patients given infliximab ( $26 \%$ over 27 weeks of follow-up versus $16 \%$ of placebo-treated patients over 20 weeks of follow-up), there was no increased risk of serious infections. There was no difference in the overall mortality rate between the groups. While low titres of autoantibodies developed in less than $10 \%$ of patients, drug-induced lupus was seen in less than $1 \%$, with these cases resolving upon discontinuation of the drug. Overall, infliximab showed an acceptable safety profile.
\end{abstract}

Key Words: Crohn's disease; Infliximab; Long term use; Safety

\section{Innocuité à long terme de l'infliximab}

RÉSUMÉ : L'infliximab, un anticorps monoclonal chimérique contre le facteur de nécrose tumorale alpha, a fait l'objet d'étude en vue du traitement de la maladie de Crohn et de la polyarthrite rhumatoïde. Dans plusieurs essais cliniques contrôlés contre placebo et menés sur échantillon aléatoire ainsi que dans des essais ouverts, 771 patients ont reçu de l'infliximab, tandis que 192 autres patients ont reçu un placebo. La période de suivi pour vérifier l'innocuité du médicament s'est échelonnée sur trois ans, auxquels il faut ajouter la durée de l'étude elle-même ( 12 semaines après la dernière perfusion). Dix-sept pour cent des patients ayant reçu une perfusion d'infliximab ont manifesté des réactions aiguës (céphalée, fièvre, frissons, urticaire, douleur thoracique) comparativement à $7 \%$ pour les patients ayant reçu un placebo. Même si, dans l'ensemble, on a observé une fréquence plus élevée d'infections chez les patients ayant reçu l'infliximab ( $26 \%$ sur 27 semaines de suivi contre $16 \%$ sur 20 semaines de suivi chez les patients ayant reçu un placebo), le risque d'infection grave n'a pas augmenté. Quant au taux de mortalité, aucune différence n’a été enregistrée entre les deux groupes. Tandis que de faibles dosages d'auto-anticorps ont été signalés chez moins $10 \%$ des patients, le lupus d'origine médicamenteuse s'est installé chez moins de $1 \%$ de ces patients, et l'affection s'est résorbée à la suite de l'interruption du médicament. Dans l'ensemble, l'infliximab présente un profil d'innocuité acceptable.
$\mathrm{T}$ umour necrosis factor-alpha (TNF- $\alpha$ ) is an important proinflammatory cytokine that mediates the production of other inflammatory cytokines and plays a pivotal role in the pathophysiology of a number of inflammatory disorders, including Crohn's disease and rheumatoid arthritis. Blocking TNF- $\alpha$ has been associated with substantial clinical efficacy in patients with Crohn's disease (1-4) or rheumatoid arthritis (5-9). However, TNF- $\alpha$-blocking agents have a potential for serious adverse events, including an increased susceptibility to infection, increased risk of developing cancer and the development of autoantibodies.

A chimeric anti-TNF- $\alpha$ monoclonal antibody, infliximab (REMICADE, Centocor Inc, USA) is a potent antiinflammatory agent that binds to TNF- $\alpha$ with a high affin- ity, avidity and specificity. Infliximab neutralizes the biological activity of TNF- $\alpha$ by binding to the soluble and transmembrane forms of TNF- $\alpha$ and inhibiting the binding of TNF- $\alpha$ with its receptors (10-12). Cells expressing transmembrane TNF- $\alpha$ bound by infliximab can be lysed in vitro by complement or effector cells (11). Infliximab binds only TNF- $\alpha$, unlike anti-TNF- $\alpha$ technologies that use the recombinant human $\mathrm{p} 55$ or $\mathrm{p} 75$ TNF- $\alpha$ receptor fused to a human immunoglobulin Fc fragment (which bind both TNF- $\alpha$ and another proinflammatory cytokine, lymphotoxin-alpha [TNF- $\beta]$ ).

The safety of infliximab has been established in both open-label and randomized, controlled clinical trials in patients with Crohn's disease and rheumatoid arthritis, with 
TABLE 1

Studies of infusion reactions in patients taking infliximab

\begin{tabular}{lcc}
\hline Infusion & Placebo $(\mathbf{n = 1 9 2 )}$ & $\begin{array}{c}\text { Infliximab } \\
(\mathbf{n}=771)\end{array}$ \\
\hline Infusions & 2121 & 4797 \\
Infusions per patient & 5.4 & 6.2 \\
Infusions with reactions & $2.1 \%$ & $4.8 \%$ \\
Serious reactions & $0 \%$ & $0.5 \%$ \\
Discontinuation & $0 \%$ & $1.9 \%$ \\
\hline
\end{tabular}

TABLE 2

Studies of the incidence of deaths in patients taking infliximab

\begin{tabular}{lcccc}
\hline & \multicolumn{2}{c}{$\begin{array}{c}\text { Crohn's disease } \\
\text { studies* }\end{array}$} & \multicolumn{2}{c}{ All studies $^{+}$} \\
Deaths & Control & Infliximab & Control & Infliximab $^{*}$ \\
\hline $\begin{array}{c}\text { Deaths per patient- } \\
\text { year of follow-up } \\
\text { Incidence per } \\
\text { patient-year }\end{array}$ & $0 / 52$ & $2 / 427$ & $3 / 190$ & $15 / 1395$ \\
\hline
\end{tabular}

${ }^{*}$ Combined studies in patients with Crohn's disease; ${ }^{+}$Combined studies in patients with Crohn's disease and with rheumatoid arthritis

over $90 \%$ of the patients in this cohort having been studied in double-blind, randomized, placebo controlled clinical trials. These trials have evaluated safety for patients while they were on study (usually through 12 weeks following the last infusion of infliximab or placebo) as well as in a three-year prospective follow-up program.

The integrated safety database comprises information from 913 patients: 771 patients treated with infliximab and 192 patients treated with placebo. Some patients who were initially randomly assigned to receive placebo subsequently received infliximab in open-label extension arms of the studies. These patients are included in both treatment groups for analysis of safety events, but are included in the placebo group analysis only up to the time that they received infliximab, and then they were included in the infliximab group analysis. Because of the crossover of placebo-treated patients to infliximab treatment groups, the average duration of follow-up in the placebo-treated group is less than in the infliximab-treated group. Data were obtained from 12 clinical trials: six in rheumatoid arthritis $(n=660)$, four in Crohn's disease $(n=233)$ and two in other inflammatory diseases (ulcerative colitis, metastatic Crohn's disease and multiple sclerosis, $n=19$ ). The data from studies in these different diseases can be pooled because the disease states have comparable immunological characteristics and because most of the patients were receiving concurrent immunomodulatory therapy, including 6-mercaptopurine, azathioprine, methotrexate and corticosteroids. The reader's interpretation of the safety data from the placebo groups should take into consideration that most of these patients were receiving immunomodulatory therapy.
Data on the safety of infliximab are available with regard to death, infusion reactions, infections, development of antibodies to infliximab, and development of autoantibodies and autoimmune disorders other than rheumatoid arthritis or Crohn's disease. Five new and two recurrent malignancies were observed in six of the 771 patients treated with infliximab in clinical trials (unpublished data). The malignancies were nonHodgkin's B-cell lymphoma, breast cancer, melanoma, squamous cell cancer of the skin and basal cell cancer. There are insufficient data to determine whether infliximab contributed to the development of these malignancies because the observed rates and incidences were similar to those expected for the populations studied. Additional details regarding infliximab safety can be found in the infliximab package insert and summary of product characteristics (13).

\section{INFUSION-RELATED REACTIONS}

An acute infusion reaction was defined as any adverse event occurring during the infusion or within 1 to $2 \mathrm{~h}$ after the infusion. Seventeen per cent of infliximab-treated patients in all clinical trials experienced an infusion reaction, compared with $7 \%$ of placebo-treated patients. Approximately $4 \%$ of infusions were accompanied by nonspecific symptoms such as headache, nausea, fever or chills; approximately $1 \%$ were accompanied by pruritus or urticaria; approximately $1 \%$ were accompanied by cardiopulmonary reactions (primarily chest pain, hypotension, hypertension or dyspnea); and approximately $0.1 \%$ were accompanied by combined symptoms of pruritus/urticaria and cardiopulmonary reactions. Table 1 summarizes the number of placebo and infliximab infusions that have been administered in clinical trials, the average number of infusions per patient and the percentage of infusions associated with a reaction. About $0.5 \%$ of infusions were associated with a serious reaction. Less than $2 \%$ of patients discontinued infliximab because of infusion reactions.

In a separate clinical trial in which patients were readministered infliximab following a two- to four-year period without infliximab treatment, 10 of 40 patients experienced adverse events three to 12 days after reinfusion. Signs and symptoms included myalgia and/or arthralgia with fever and/or rash, with some patients also experiencing pruritus; facial, hand or lip edema; dysphagia; urticaria; sore throat; and headache. Nine of 10 patients experiencing these events had initially received a liquid formulation of infliximab that is not used commercially. Patients' signs and symptoms improved substantially or resolved with treatment in all cases. There is little experience regarding the incidence of these events after drug-free intervals of less than two years. However, these delayed reactions have not been observed in clinical trials in which Crohn's disease and rheumatoid arthritis patients were treated every eight weeks $(3,8)$.

\section{DEATHS}

Table 2 reports the incidence of death through three years of follow-up in the integrated safety database. When all studies were combined, there was no difference in the incidence of death between the placebo-treated and infliximab-treated 
groups. The deaths in the two patients with Crohn's disease treated with infliximab were associated with lymphoma and a myocardial infarction.

\section{INFECTIONS}

Infections have been reported by $26 \%$ of infliximab-treated patients (average of 27 weeks of follow-up) and by $16 \%$ of placebo-treated patients (average of 20 weeks of follow-up). The infections most frequently reported were upper respiratory tract infections, including sinusitis, pharyngitis and bronchitis, and urinary tract infections. No increased risk of serious infections or sepsis has been observed with infliximab compared with placebo (Table 3). Pneumonia, cellulitis, urinary tract infection and sepsis were the most frequently reported serious infections in placebo- and infliximab-treated patients (Table 4). A generalized immunosuppression does not occur in patients treated with infliximab. Peripheral blood lymphocytes from infliximab-treated patients showed no significant decrease in number or proliferative responses to in vitro mitogenic or antigenic stimulation compared with cells from untreated patients (13).

\section{IMMUNOGENICITY}

Antibodies to infliximab can develop after treatment. One hundred and thirty-four of 199 patients with Crohn's disease treated with infliximab were evaluated for the development of infliximab-specific antibodies. Many of the patients who could not be evaluated for the presence of antibodies continued to have measurable levels of infliximab in serum samples, even 12 weeks after the last infusion of infliximab. Serum infliximab interferes with the assay for detecting antibodies to infliximab. Eighteen patients (13\%) were antibody positive (the majority at low titre, less than 1:20). Antibody development was lower among patients receiving immunomodulatory therapies such as 6-mercaptopurine, azathioprine or methotrexate. The clinical relevance of antibody development is uncertain because some patients who have developed antibodies have continued to receive infliximab with sustained efficacy and tolerability (3).

\section{AUTOANTIBODIES AND DRUG-INDUCED LUPUS}

Studies in animals have associated TNF- $\alpha$ deficiency or inhibition with the development of a lupus-like condition $(14,15)$. Development of antinuclear antibodies (ANA) and antidouble-stranded (ds) DNA antibodies have been reported with anti-TNF- $\alpha$ agents $(13,16)$. Of patients with Crohn's disease treated with infliximab who were evaluated for ANAs, 34\% developed ANA between screening and the last evaluation. Anti-dsDNA antibodies developed in approximately $9 \%$ of infliximab-treated patients, usually at low levels. Approximately 20\% of patients with Crohn's disease were positive for ANA at screening, but none were positive for anti-dsDNA. In some cases, titres of ANA and antidsDNA normalized while patients received infliximab.
TABLE 3

Studies of the incidence of serious infections in patients taking infliximab

\begin{tabular}{lcccc}
\hline & \multicolumn{2}{c}{$\begin{array}{c}\text { Crohn's disease } \\
\text { studies* }\end{array}$} & \multicolumn{2}{c}{ All studies $^{\dagger}$} \\
& Control & Infliximab & Control & Infliximab \\
\hline $\begin{array}{c}\text { Patients with serious } \\
\text { infection per } \\
\text { patient-year of } \\
\text { follow-up }\end{array}$ & $1 / 23$ & $6 / 152$ & $7 / 88$ & $26 / 517$ \\
$\begin{array}{c}\text { Serious infections per } \\
\text { patient-year of } \\
\text { follow-up }\end{array}$ & $1 / 23$ & $7 / 152$ & $10 / 88$ & $35 / 517$ \\
$\begin{array}{l}\text { Incidence per } \\
\text { patient-year }\end{array}$ & 0.044 & 0.046 & 0.114 & 0.064 \\
\hline
\end{tabular}

*Combined studies in patients with Crohn's disease; ${ }^{+}$Combined studies in patients with Crohn's disease and with rheumatoid arthritis

TABLE 4

Studies of types of serious infections in patients taking infliximab

\begin{tabular}{lcc}
\hline Infection & Control $(\mathbf{n = 1 9 2 )}$ & Infliximab $(\mathbf{n}=\mathbf{7 7 1})$ \\
\hline Pneumonia & $1(0.5 \%)$ & $9(1.2 \%)$ \\
Cellulitis & $0(0.0 \%)$ & $4(0.5 \%)$ \\
Sepsis & $2(1.0 \%)$ & $4(0.5 \%)$ \\
Skin ulceration & $1(0.5 \%)$ & $1(0.1 \%)$ \\
Urinary tract infection & $2(1.0 \%)$ & $0(0.0 \%)$ \\
Abscess & $1(0.5 \%)$ & $1(0.1 \%)$ \\
\hline
\end{tabular}

Three of 771 patients $(0.39 \%)$ developed symptoms of drug-induced lupus during the study: one patient with Crohn's disease (migratory arthritis) and two patients with rheumatoid arthritis (one with pleuropericarditis and one with a butterfly-pattern facial skin rash and forearm rash). None of these patients had renal or central nervous system complications, and symptoms resolved with the discontinuation of infliximab and short term medical management. No other lupus-like conditions were observed during the long term follow-up period.

\section{CONCLUSIONS}

During the long term prospective safety follow-up of patients treated with infliximab in clinical trials, a favourable safety profile has been observed. Less than $2 \%$ of patients have had infusion reactions that required discontinuation of therapy. Although the incidence of mild infections, primarily upper respiratory infections, are increased in patients receiving infliximab, no increase in the incidence of serious infections has been observed. Low titres of autoantibodies develop in less than $10 \%$ of treated patients, but drug-induced lupus occurs infrequently and is reversible with discontinuation of 
therapy. Infliximab continues to demonstrate a favourable benefit-risk relationship.

\section{REFERENCES}

1. Targan SR, Hanauer SB, van Deventer SJH, et al. A short-term study of chimeric monoclonal antibody cA2 to tumor necrosis factor for Crohn's disease. Crohn's Disease cA2 Study Group. N Engl J Med 1997;337:1029-35.

2. Present DH, Rutgeerts $P$, Targan $S$, et al. Infliximab treatment of fistulas in patients with Crohn's disease. N Engl J Med 1999;340:1398-1405.

3. Rutgeerts P, D'Haens GR, Targan SR, et al. Efficacy and safety of retreatment with anti-tumor necrosis factor antibody (infliximab) to maintain remission in Crohn's disease. Gastroenterology 1999;117:761-9.

4. van Dulleman HD, van Deventer SJH, Hommes DW, et al. Treatment of Crohn's disease with anti-tumor necrosis factor chimeric monoclonal antibody (cA2). Gastroenterology 1995;109:129-35.

5. Elliott MJ, Maini RN, Feldmann M, et al. Treatment of rheumatoid arthritis with chimeric monoclonal antibodies to tumor necrosis factor a. Arthritis Rheum 1993;36:1681-90.

6. Elliott MJ, Maini RN, Feldmann M, et al. Randomised double-blind comparison of chimeric monoclonal antibody to tumor necrosis factor alpha (cA2) versus placebo in rheumatoid arthritis. Lancet 1994;344:1105-10.

7. Maini RN, Breedveld FC, Kalden JR, et al. Therapeutic efficacy of multiple intravenous infusions of anti-tumor necrosis factor alpha anti-tumor necrosis factor alpha monoclonal antibody) versus placebo in rheumatoid arthritis patients receiving concomitant methotrexate: a randomised phase III trial. Lancet 1999;354:1932-9.

9. Kavanaugh A, St Clair EW, McCune WJ, Braakman T, Lipsky P. Chimeric anti-tumor necrosis factor-alpha monoclonal antibody treatment of patients with rheumatoid arthritis receiving methotrexate therapy. J Rheumatol 2000;27:841-50.

10. Knight DM, Trinh H, Le J, et al. Construction and initial characterization of a mouse-human chimeric anti-TNF antibody. Mol Immunol 1993;20:1443-53.

11. Scallon BJ, Moore MA, Trinh H, Knight DM, Ghrayeb J. Chimeric anti-TNF alpha monoclonal antibody cA2 binds recombinant transmembrane TNF-alpha and activates immune effector functions. Cytokine 1995; 7:251-9.

12. Siegel SA, Shealy DJ, Nakada MT, et al. The mouse/human chimeric monoclonal antibody cA2 neutralizes TNF in vitro and protects transgenic mice from cachexia and TNF lethality in vivo. Cytokine 1995;7:15-25.

13. REMICADE package insert. Malvern: Centocor, 1999.

14. Via CS, Rus V, Shustov A, Nguyen, P, Finkelman F. Administration of anti-tumor necrosis factor (TNF) monoclonal antibody (MAB) induces lupus-like autoimmunity in the parent-into-f1 (P-F1) model of monoclonal antibody combined with low-dose weekly methotrexate in rheumatoid arthritis. Arthritis Rheum 1998;41:1552-63.

8. Maini RN, St Clair EW, Breedveld FC, et al. Infliximab (chimeric acute graft versus host disease (GVHD). Arthritis Rheum 1996;39:S108.

15. Jacob CO, McDevitt HO. Tumor necrosis factor-alpha in murine autoimmune "lupus" nephritis. Nature 1988;331:356-8.

16. ENBRO package insert. Seattle: Immunex Corporation, 2000. 


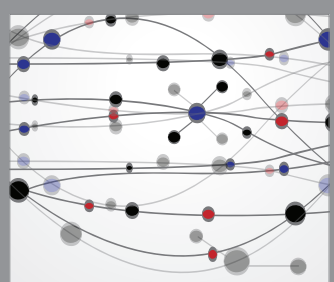

The Scientific World Journal
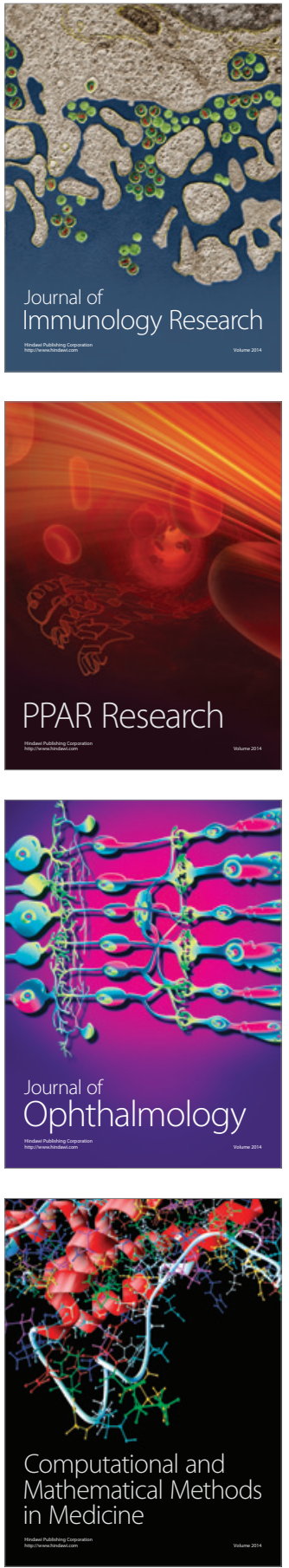

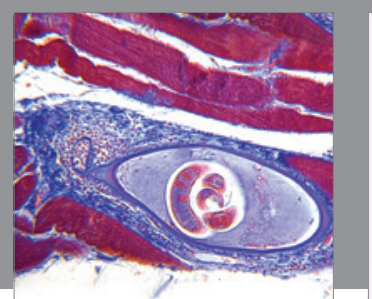

Gastroenterology Research and Practice

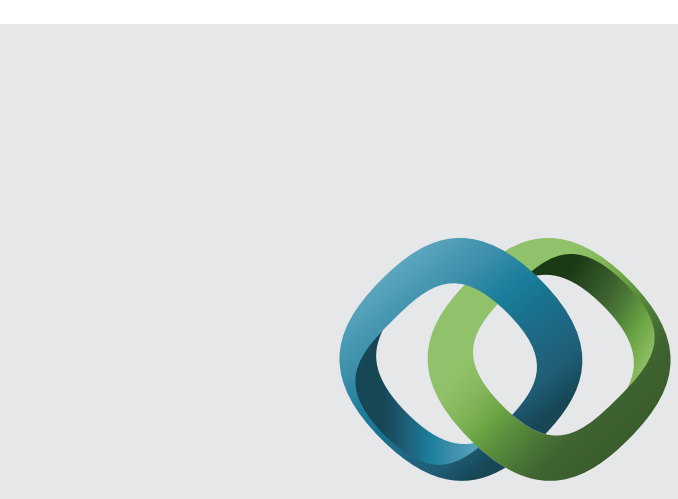

\section{Hindawi}

Submit your manuscripts at

http://www.hindawi.com
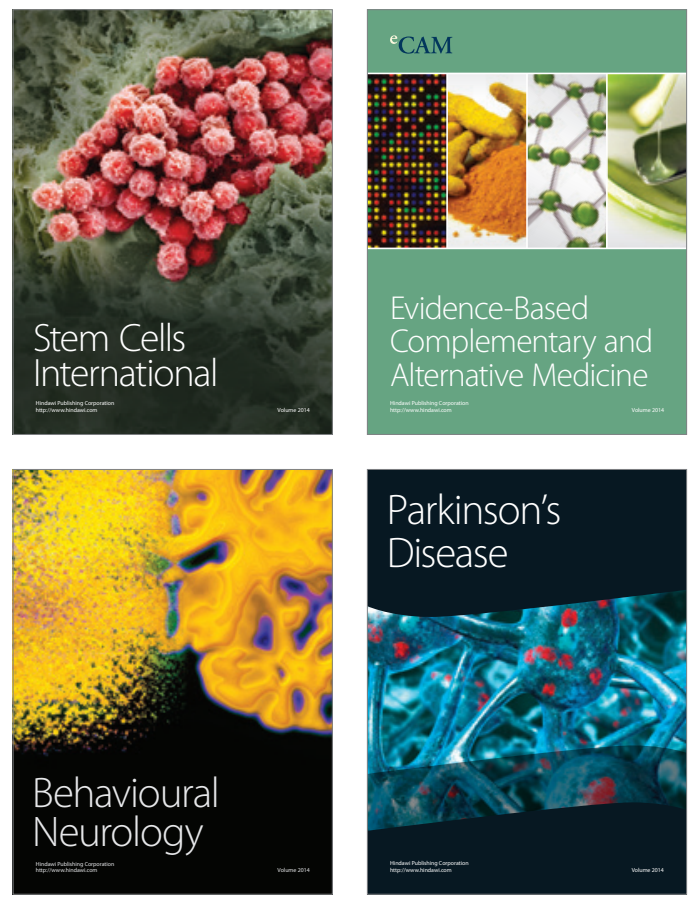
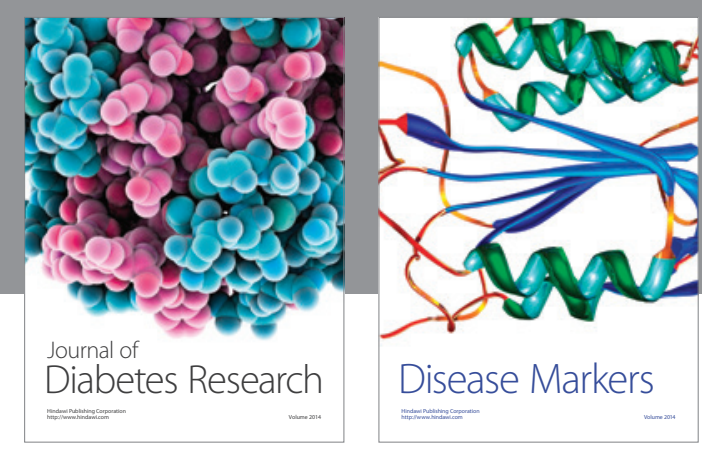

Disease Markers
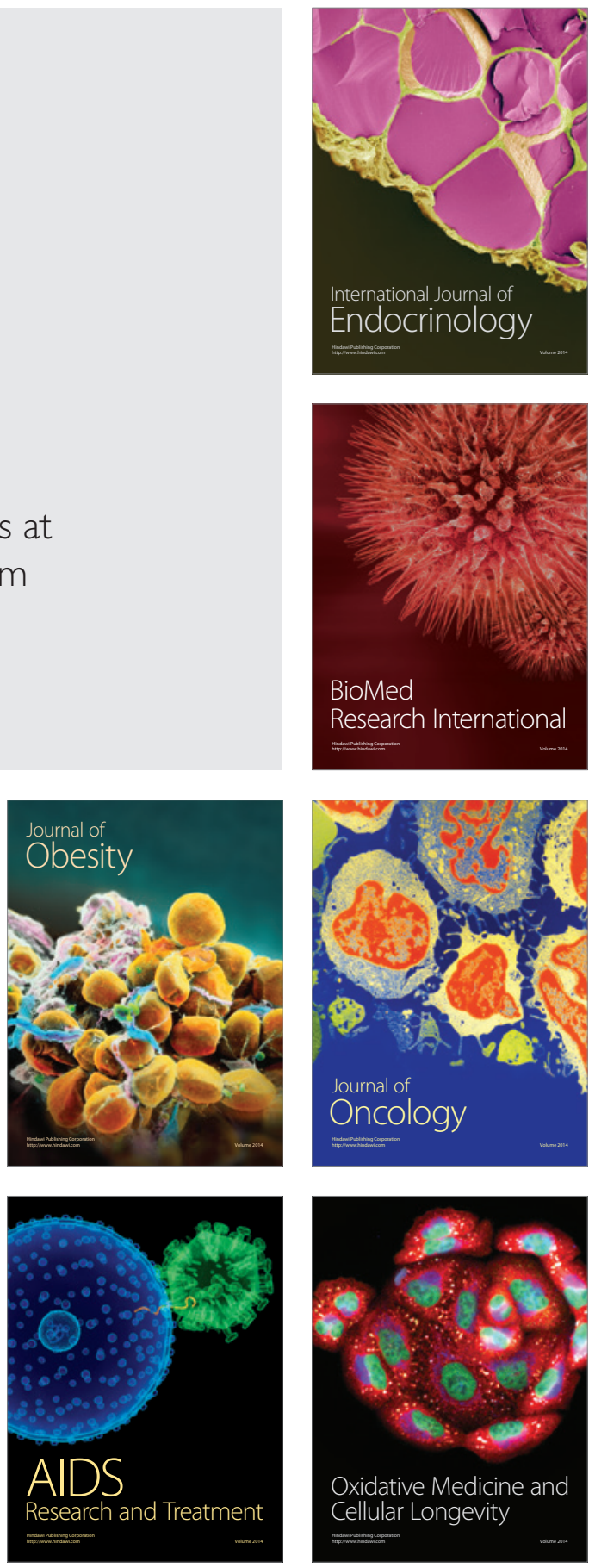